\title{
A TRAVESTI, O VATICANO E A SALA DE AULA
}

\author{
Sara Wagner Pimenta Gonçalves Júnior
}

\section{Resumo}

O presente artigo dialoga com a emergência das discussões iniciais sobre a ideologia de gênero. Tensões sobre identidade de gênero e orientação sexual, e agenciamentos na articulação da categoria "ideologia de gênero". Trata se de uma composição pessoal, cuja escrita marca minha estreia enquanto travesti, nas salas de pós graduação, onde e quando ocorreram minhas compreensões iniciais sobre pânico moral, retrocesso e controvérsias públicas. Logo, é uma composição a partir de minhas lentes enquanto não homem histórico, deficiente visual, mulher latinoamericana, travesti e moradora na Região dos Lagos no Rio de Janeiro e, portanto, reflito sobre as conexões com a realidade vivenciada por mim em sala de aula. Para discutir com tais questões lanço mão das reflexões desenvolvidas por Carrara (2015), Garbagnoli (2016), Junqueira (2017) e Seffner (2016) em suas pesquisas.

Palavras-chave: Ideologia de gênero. Identidade de gênero. Docência.

O presente artigo pretende dialogar com textos que trazem problematizações a partir de compreensões sobre identidade de gênero e orientação sexual, e agenciamentos na articulação da categoria "ideologia de gênero". Pretende-se também, a partir de compreensões sobre pânico moral, refletir sobre possíveis conexões com a realidade vivenciada por mim em sala de aula. Para dialogar com tais questões lanço mão das reflexões desenvolvidas pelos seguintes autores: Carrara (2015), Garbagnoli (2016), Junqueira (2017) e Seffner (2016), entre outros.

Considero a dificuldade histórica da política de educação em estabelecer diálogo com aspectos ligados à sexualidade (tema já abordado por Louro, 2000; Altmann, 2007; e Junqueira, 2009, por exemplo) um dos aspectos que cerceiam seu trato no âmbito escolar e daí a necessidade de emergência de trabalhos baseados na experiência cotidiana construída nas escolas. Essa escrita é uma tentativa de apoio às dinâmicas contra hegemônicas, e que dialogam com autores (trans) feministas. Pânicos morais, o movimento Escola sem Partido, registro civil das identidades transgênero e tantas outras emergências foram se corporificando na tentativa de responder que não, eu não seja homem, ainda que após um processo cível de correção de gênero, tal retificação me tenha sido negada. Por vezes, de 
forma reflexiva ou imediata, a resposta estaria ali de modo simplificado e essencialista, entretanto, depois de intensos mais de 40 anos vividos, o porquê dessa questão ainda ser presente, fez com que minhas próprias noções morais, éticas, estéticas e políticas fossem se materializando de modo inquietante.

Trago, para essa discussão, de modo sucinto, pontos da cena mundial que desenham aspectos anacrônicos, porém cíclicos, da substantivação dos processos que buscam invalidar corpos que importam (Butler, 2015) e que se contrapõem a processos de cidadanização da diversidade sexual e de gênero (Carrara, 2016) em múltiplos espaços. A dor de ser transgênero ${ }^{56}$ no Brasil, é uma dor na alma, não pode ser sentida por quem não é transgênero, talvez verificada, mas não sentida, ainda que padrões de passabilidade ${ }^{57}$ existam. Não é percebido porque ser cisgênero ${ }^{58}$ é estar na consonância, e não estar nela significa estar no sentimento de alerta cotidianamente. Estar travesti, é ser percebida como ameaça, ou você é engraçada, ou inteligente, ou sexy ou uma bobagem qualquer, mas nunca alguém com significados que não sejam estes. O discurso se molda, a partir de um fato acontecido, trazido em uma narrativa própria (Josso, 2004), logo, por ler a escrita de outros, me elaboro enquanto sujeito a partir desta escrita, pensando os atos de currículo e, as micros ousadias clandestinas (Macedo, 2013) e o pânico moral $\left(\right.$ Cohen ${ }^{59}$ ). Tais aspectos atravessam minha história sobremaneira, não apenas por estar no grupo $\mathrm{LGBTI}_{+}^{60}$, mas por ser pessoa $\mathrm{T}^{61}$ sem o recurso da passabilidade

\footnotetext{
${ }^{56}$ Segundo a Associação Americana de Psicologia, transgênero é um termo guarda-chuva, para pessoas cuja identidade de gênero, expressão de gênero ou comportamento não está de acordo ou que é tipicamente associado ao sexo que thes foi atribuído no nascimento. A identidade de gênero refere-se a sentido interno da pessoa de ser homem, mulher, ou alguma outra denominação; expressão de gênero se refere à maneira como uma pessoa comunica gênero e identidade aos outros através do comportamento, vestuário, penteados, voz ou características do corpo. https://www.apa.org/topics/lgbt/transgender.pdf

57 Passabilidade de modo sucinto, pode ser compreendida como privilégio experienciado por pessoas transgênero, que após algum tipo de recurso (cirúrgico, hormonal ou ciborque) passa a ser percebida como pessoa cisgênero. PONTES E SILVA (2018)

${ }^{58}$ A noção de cisgeneridade é proposta pela transexual Julia Serano em 2007 na obra Whipping Girl: A Transsexual Woman on Sexism and the Scapegoating of Femininity a partir do exercício de analisar a origem da terminologia -trans-: o outro, o desajuste.

${ }^{59} 1^{\text {a }}$ edição 1972; $2^{\text {a }}$ edição 1980 (10 anos depois); $3^{\text {a }}$ edição 2002 (30 anos depois) é uma Introdução à $3^{\text {a }}$ edição: intro à $2^{\mathrm{a}}$ ("Simbolos de problemas") tratou dos "folk devils" (sobretudo abordagens teóricas da época na área das teorias subculturais da delinquência desenvolvidas no Centre for Contemporary Cultural Studies [CCCS] de Birmingham, referência da sociologia britânica [dirigido por Stanley Hall a partir de 1968] e fechado em 2002); intro à $3^{\text {a }}$ ("Panicos morais como politica cultural") aborda os pânicos morais (segunda parte do titulo), fazendo uma revisão dos usos e críticas do conceito nesses 30 anos passado.

${ }^{60} \mathrm{LGBTI}$, sigla guarda-chuva que abriga, lésbicas, gays, bissexuais, travesti, transgêneros, queer, gender fluid, intersexos entre outras formas variantes não condensadas na compreensão nas identidades de gênero, inteligibilidade corporal (não diáticos) e/ou Ipsosexuais (pessoas compreendidas diáticas, mas que o são por redesignação genital e orientações sexuais propostas.
} 
(passability), como explicado anteriormente. E, assim, trazem para minha vida cotidiana e prática docente, polemizações pouco ou nunca sofridas por outros atores sociais.

Desde o início da década de 1990, no contexto das Conferências Mundiais de Cairo e Pequim ${ }^{62}$, o Vaticano contesta o conceito de gênero forjado pelas feministas, que buscavam rever a ordem tida como natural, nos arranjos sociais. Garbagnoli (2016) afirma que

"Ideologia de gênero" é um novo dispositivo retórico produzido tanto para deslegitimar feministas LGBTQ que estudam, lutam e reafirmam que as normas sexuais transcendem os aspectos históricos e arranjos políticos. Ele também investiga como a transnacionalidade deste construto discursivo refere-se às características específicas assumidos em dois contextos nacionais diferentes_França e Itália (Garbagnoli, 2016)

Apesar dessa autora debater acontecimentos ocorridos em parte da Europa, podemos ver seus desdobramentos em outros países de fé cristã, onde a lgreja Católica exerce grande influência. Quando ela propõe que examinemos a retórica e estratégias performativas dos protagonistas antigênero, podemos entender como uma reação política contra a entrada de minorias sexuais nos campos do ativismo e da produção acadêmica poderiam ser eficazes no apagamento epistemológico destes grupos. Garbagnoli nos traz que, a partir de um relatório anual de 2012 o Observatório Internacional Cardeal Van Thuán (CVTIO), instituído em 2004 para difundir a doutrina social da Igreja Católica, se abre para uma discussão que consideram ser a "questão do ano". O documento aponta a "colonização da natureza humana" produzida por gênero em 2012, a crise jurídica induzida por "relativismos" em 2013, e o feminismo como um novo totalitarismo, em 2014. Então de forma incisiva, a igreja católica, mais especificamente, arregimenta, intelectuais (professores, antropólogos, biólogos e tantos outros estudiosos) que atuam em suas universidades e, também nas igrejas, para que a cada nova elaboração no campo feminista, outra elaboração seja trazida em contraponto. Como reitera Garbagnoli (2016),

\footnotetext{
${ }^{61}$ Pessoa $T$, compreende, mulheres trans e travestis, transgêneros e homens trans ou trans-homens (parte do grupo que argumenta que ser trans precede o ser homem).

${ }^{62}$ A Conferência Mundial sobre População e Desenvolvimento (Cairo, 1994) e a IV Conferência Mundial da Mulher (Pequim, 1995) estabelecem a promoção da igualdade de género, eliminação da violência contra a mulher, garantia dos direitos reprodutivos e redução da mortalidade materna e infantil, entre outras questões
} 
Na opinião de Ratzinger, a lei natural diz respeito à natureza da pessoa humana como tal e sua fundação é a complementaridade ontológica entre homens e mulheres, que se torna sinônimo de "humanidade" no discurso do Vaticano. Nesta visão, a produção de homens e mulheres como dois naturais diferentes e grupos complementares é determinado tanto pela antropologia como pela biologia, e daí o Vaticano simultaneamente se baseia em teologia e biologia para reafirmar a transcendente natureza da ordem sexual. (p. 122)

Ao se posicionar dessa forma, Bento XVI, diz que outras formas de pensar as subjetividades humanas no campo dos estudos sociais (naquele momento as feministas e suas abordagem no campo dos estudos de gênero e sexualidade) estariam desafiando a "base imutável da antropologia", tornando-se assim, ameaçadores da "ordem da criação" e a estabilidade da reprodução social (Bento XVI, 2008, apud Garbagnoli, 2016). A conceituação do Vaticano da "ideologia de gênero" é construída, então, como novo dispositivo retórico. Segundo a autora, o Vaticano, afirma que as normas sexuais não seriam históricas, tampouco políticas.

Ao analisar a estrutura do discurso antigênero, Garbagnoli (2016) e Fassin (2011) se remetem à combinação de dois elementos: as especificidades do próprio dispositivo antigênero e as características dos contextos nacionais em que se desenvolvem. Tal discurso é largamente aceito em vários países e assume regras locais convenientes, adequando-as a sua cultura nacional (Junqueira, 2017). A força impregnada pelo Vaticano à chamada "ideologia de gênero" que funciona como um dispositivo discursivo, está em sua forma quando traz um discurso católico, apresentado como uma evidência antropológica sobre a natureza humana (Garbagnoli, 2016). Como propõe Junqueira (2017), construído de uma forma transnacional, a "ideologia de gênero" é um significante vazio ajustando-se a diferentes contextos nacionais e complexos temas ligados à sexualidade.

Diferentes atores que apoiam a crença que as normas sexuais transcendem a história difundiram esta construção retórica, adaptando-a com sucesso a diversos contextos nacionais, criando assim, uma circulação transnacional de argumentos e ações sustentadas por formas complexas de intertextualidade e conexões. Segundo Garbagnoli (2016):

Articulado em textos e realizado e ritualizado nas manifestações de rua, essa luta contra a desnaturalização da ordem sexual operou como um ato instituinte produzindo o que enuncia (Bourdieu, 2001). "Ideologia de gênero" agora existe no contexto francês e italiano como categoria de percepção, 
mobilização e ação. Este dispositivo retórico age eficazmente porque reafirma de uma nova maneira que a ordem sexual transcende a história. Essa crença, longe de ser específica para a Igreja Católica, é amplamente compartilhada por muitos atores sociais.

Graças à força dos arranjos que reafirmam a naturalização das normas sexuais, sexo e sexualidade tendem ser percebidos socialmente como fatos naturais. Assim, estudos de gênero e de sexualidade, casamento entre pessoas do mesmo sexo, educação em gênero e sexualidade para crianças e adolescentes, reformas escolares ou legais ligadas a esses temas, saúde sexual e reprodutiva como direitos, são enunciados como "ideologia de gênero", gerando pânicos morais. Cohen (1972) se propôs a fazer um estudo de caso denominado "Mods e Rockers", que se estendeu pela maior parte da década de 1960, para ilustrar características dos episódios coletivos de delinquência juvenil e pânicos morais por eles gerados e que contribuem para sua expansão, como veremos mais adiante. Segundo o autor:

na galeria de tipos que a sociedade elege para mostrar aos seus membros que papeis devem ser evitados e quais devem ser emulados, esses grupos ocuparam uma posição constante como 'demônios populares': lembretes visíveis do que não devemos ser. As identidades desses tipos sociais são propriedade pública, e esses grupos de adolescentes em particular vêm simbolizando - tanto no que são quanto no modo como se reage a eles - boa parte da mudança social ocorrida no Reino Unido nos últimos 20 anos. (Cohen, 1972, p. 134)

O "gênero", sempre trouxe preocupação para o Vaticano, seja como um sistema que produz homens e mulheres como dois grupos complementares naturais, funcionando "como uma cosmologia: um mundo sem gênero parece impensável" (Delphy, 2001 p. 31) ou reiterando que outras expressões de gênero e seus trânsitos, seriam indiscutíveis, dada sua atuação, não legítima. Essa perspectiva se afirma a partir de uma norma, e seus defensores "sonham" com um momento em que todos seremos iguais. Assim, diante da uniformização, como ficaria quem desse modo transcende? Os estudos de gênero se afastam de uma perspectiva de universalização. Contudo, a suposta liberdade de todos e todas, a partir de um olhar para suas subjetividades, vem junto com uma norma que pressupõe a diferença, por isso a universalização das compreensões do ser homem e ser mulher. "Que não se fixe a categoria gênero", propõe Angela Davis (2018), mas como não fixá-la enquanto a descrevemos? Poderíamos partir do ponto descritivo e fixo, mas ao 
compreender o modo como essa dinâmica reforça opressões, retorno à afirmativa da autora, "que não se fixe a categoria de gênero".

Logo, teorias feministas ou LGBT e reivindicações contrastantes à ideia de que os sexos são grupos naturais e complementares, desestabilizariam profundamente tais crenças entranhadas na cultura. O Vaticano elege então, o gênero, mas especificamente, a "ideologia de gênero" para seu uso como arma de controle. Como ressalta Scott (2013), "O que perturba a Igreja Católica não é o gênero em si - gênero pode ser usado de maneira naturalista e normativa como sinônimo de 'mulheres' como um 'grupo natural' -, mas o gênero como um conceito crítico desnaturalizador da ordem sexual".

Ao se opor às teorias que afirmam que masculinidade e feminilidade são construções sociais, como na análise feminista, o Vaticano lança que essa desconstrução da ordem sexual nos levaria à "autodestruição da humanidade" (Bento XVI, apud Garbagnoli, 2016), uma vez que isso contradiz a "divisão irrevogável e inevitável, além disso, manifesta-se em corpos e almas: nas diferenças anatômicas entre homens e mulheres e em suas disposições complementares" (Stein, 2008). Segundo Stein, o sexo é considerado aceitável quando é definido como "fundamentado em identidade sexual biológica, masculina ou feminina" (Delegação 1995 da Santa Sé; PCF 2005).

Ao trazer à tona, o assunto "gênero", o Vaticano reage ao surgimento de estudos feministas e LGBTQ, analisando os arranjos sociais através dos quais normas são naturalizadas (Guillaumin, 1995). Utilizam também de modo intencionalmente equivocado e parcial autoras que consideram expoentes no assunto como Judith Butler e Monique Wittig. Retornam às reivindicações dos movimentos feministas e LGBTQ contra o sistema de arranjos que oprimem as mulheres e as pessoas não heterossexuais (Eleftheriadis 2015). E por fim, opõe-se às reformas legais e políticas públicas que visem reduzir as discriminações contra as mulheres ou as pessoas LGBTI. Como reitera Garbagnoli (2016),

Quando usado no campo do gênero e estudos de sexualidade, o gênero tem significados diferentes referentes a teorias da ordem sexual (Mathieu 1991) e não é necessariamente o mesmo significado quando usado por juristas ou políticos. Daí o sintagma "teoria de gênero" e " ideologia de gênero ", como elas começaram a circular em discursos públicos, mídia, produziu uma proliferação de discursos sobre gênero caracterizados por forma de "inter-incompreensão estrutural" 
(Maingueneau, 1983). Em terceiro lugar, "ideologia de gênero" procura legitimar a retórica anti-gênero como uma abordagem racional e cientifica do discurso.

Assim como no caso, Mods e Rockers (Cohen, 1972) ocorrido na década de 1960 no Reino Unido, o conflito "mods versus rockers" deu origem a um pânico moral voltado contra a juventude moderna na Grã-Bretanha, influenciando jovens quanto ao gosto musical, vestimenta e outras formas culturais. Como afirma Cohen (1972), apesar da "febre", "cinco anos depois, esses grupos praticamente desapareceram da consciência pública, permanecendo na memória coletiva como bodes expiatórios ${ }^{63}$, do passado, aos quais os horrores atuais podem ser comparados" (p. 3).

Por se tratar de uma condição, episódio, pessoa ou grupos de pessoas, que emerge para ser definido como uma ameaça aos valores e interesses sociais, a ideia de pânico moral (Cohen apud. Rubin, 1984) propõe que alguns grupos lidos como "não autorizados" pela sociedade, poderiam se tornar alvo de possível desajuste à forma, norma, estrutura ou condição atual. Uma abordagem transacional e interacionista do desvio aparecem, onde o foco em como a sociedade classifica aqueles, aquelas ou aqueles, que quebram as regras como pertencentes a determinados grupos desviantes. Uma vez assim classificados, seus atos são interpretados em termos do status que Ihes foi atribuído. São formas acionadas por alguns grupos (nem sempre hegemônicos) na composição da negação de epistemologias outras, com validação factível por parte daqueles que no grupo majoritário se encontram. Carrara (2015), ao discutir a emergência da noção de direitos sexuais como aspecto central de um processo mais amplo de transformação que acontece no nível das políticas sexuais, afirma que "A sexualidade era, portanto, um interesse de Estado a que deviam estar submetidos os interesses particulares. Nesse âmbito, apenas tais entes transcendentais teriam "direitos"; os indivíduos tinham, sobretudo, obrigações e deveres" (Carrara, 2015).

Nas teorias sociais, falamos em pânico moral, uma vez que, não é permissível a exclusão de grupos quaisquer, em prioridade de outrem. Os pânicos morais são recorrentes com grupos minoritários e que sofrem alguma forma de preconceito, como por exemplo, atualmente contra imigrantes nos EUA, quando

\footnotetext{
63 "Folk devils" [literalmente, "demônios do povo"]: expressão cunhada por Cohen, às vezes traduzida como "bodes expiatórios" - tradução perde a ideia da "demonização"; caráter religioso dá noção da intensidade dos sentimentos envolvidos, assim como "pânicos".
} 
estes seriam uma ameaça ao cidadão americano e seus direitos constituídos. No Brasil, a reação contra a população LGBT se mantém, mesmo após a redemocratização do país. Os discursos em torno da diversidade sexual e de gênero acionam pânicos ligados à possibilidade de destruição da família, ideologização da escola e desvirtuamento das crianças. Este dispositivo de controle envolve seus interlocutores de forma a criar uma histeria e aderência coletiva contra determinados grupos particulares. Tais participantes envolvem-se, com ideias de controle, que irmanadas à compreensão da "ideologia de gênero" tem ganhado espaço na arena pública. Nesse sentido, diferentes autores apontam para a existência de um backlash $^{64}$ (Faludi, 1991), categoria que expressaria o retorno de situações, ações ou grupos, formando um movimento que tenta retroceder em direitos já garantidos. Um exemplo disso seria uma reação que tenta retirar mulheres e LGBTs da cena pública, no campo do direito e igualdades.

A partir dessas reflexões, trago uma experiência vivida por mim, que pode ilustrar e provocar novas reflexões. Sendo mulher trans e/ou travesti e ativista nos movimentos sociais LGBTQI+, recebi no dia 18/03/2018, através de uma rede social, um pedido de ajuda de uma aluna que se identificava como lésbica e que estaria sofrendo bullying por parte de alguns alunos da escola, que apesar de pública tem em sua direção, conteúdos cristãos priorizados. Dizia ela: "não sei mais o que fazer, são meus amigos e me sinto cada vez mais distante deles, a Xxxx e a Xxxx foram orientadas a se afastarem, as mães delas não querem que estejamos juntas. Me sinto muito mal, nós nunca tivemos nada!"

Buscando entender os fatos, em 19 de março de 2018, durante uma aula e acreditando que poderia perceber melhor os movimentos que demonstrassem (in)formações destes alunos, sobre suas impressões acerca de diferentes sexualidades e direitos da população LGBT, lancei mão da proposta de trazer de modo solto, algumas palavras para compor a leitura de um texto que contava brevemente um encontro para execução de trabalho de matemática entre duas meninas. Ao final do texto, que em nada fazia referência a uma relação mais intensa entre as meninas, senão o fato de estarem juntas para estudar, um dos garotos diz,

64 "Backlash", termo americano que explicita um conjunto de reações (discursos, ideologias, teorias, mídia) ao feminismo, com propósito anti-feminista. Apesar de ter sido popularizado por Faludi, .Rudman, Laurie A., and Peter Glick (2001), reiteram essa visão. 
encontrando só pra estudar? Que saco... Pontuei, claro, mas poderia ser pra namorar, namorar e estudar, né?! Todos me olharam, e pontuei, Ou tem problema serem lésbicas? Fez se silêncio. Imaginei se o comentário fosse feito a partir de um casal composto por um menino e uma menina, geraria o olhar de estranheza e ainda, se fosse feito por outro perfil de educador, uma outra mulher sem características transgêneras tão demarcadas. O fato de uma menina estar falando que não sabia para onde eu estaria olhando, em referência ao alto grau de estrabismo e $(\mathrm{m})$ cegueira que possuo em um dos olhos, fez o assunto ir para outro lugar.

Senti-me muito constrangida, por sentir certa "maldade" nos sorrisos entre seus lábios e olhar lançados a outros colegas. Na sequência, seguindo na leitura do exercício, outra colocação foi ouvida com estranheza, os olhos e inquietações se fizeram novamente presentes, ao traduzirmos a palavra "Sausage", um dos alunos sugeriu, salsicha, e prontamente retruquei linguiça, buscando um certo distanciamento do que poderia ser lido como um parônimo. Aula encerrada.

No dia 20 de março de 2018, fui convidada a comparecer na escola para uma reunião com o Conselho Escolar. Por telefone a Diretora avisa que é um problema e que gostaria de verificar se o que foi dito pelos alunos, que eu estaria fazendo "apologia ao lesbianismo", era de fato verdade e que a sala de aula na totalidade havia feito uma reclamação que sem passar por qualquer outra instância foi dirigida ao mais alto setor de uma Escola, o Conselho Escolar, com o julgamento, no pensamento engendrado (Laurentis,1989).

No dia 22/03/2018, durante a reunião foi colocado em ata questões que marcam de modo negativo a minha jornada docente, como por exemplo, a validação da escrita pela direção ao trazer, segundo o que algum adolescente disse, "a professora em questão não dá aula", "ela não mescla português com inglês", "ela fala de modo pejorativo", "fazia menção a sexo enquanto falava de linguiça", "usou a palavra quicar na frente dos alunos", "usa linguajar chulo", "faltou com respeito", entre outros pontos de igual teor.

No dia 27, retornei à mesma turma, dei aula normalmente e me desculpei por algum incidente que pudesse ter gerado por falta de compreensão de algum modo ou expressão utilizada. Saí dessa sala de aula, com a sensação de ter ali pessoas que entenderam o que e sobre o que eu houvera falado. No dia 31, recebi uma ligação logo pela manhã, era da secretária de educação comunicando que eu estaria 
sendo retirada daquela sala e da escola em função da minha postura e que deveria me dirigir à Secretaria de Educação.

O discurso de defesa dos estudantes foi acionado, nesse caso, para corroborar com a exclusão da professora trans do ambiente escolar. Como discute Carrara (2013),

As atuais preocupações em relação ao sexo não consentido ou em relação ao preconceito e à discriminação homofóbica, por exemplo, têm desenhado vastas categorias de "vulneráveis". E em nome de sua proteção, instalam-se controles sobre fluxos populacionais (...) Do mesmo modo, mesmo que a heterossexualidade reprodutiva possa ser destituída de sua posição normativa, as "crianças" continuam no centro das preocupações. Posicionadas como a mais vulnerável das categorias sociais nos termos do novo regime da sexualidade, sua proteção contra a exploração e o abuso vem justificando recentemente toda uma série de controles sobre fluxos populacionais reais ou virtuais. (Carrara, 2013)

Práticas como a "Escola sem partido65" por exemplo, nos mostra como um grupo pode ser acionado em defesa de outros de maior valor. Sua atuação é mascarada com propostas para resolução daqueles problemas outrora propostos. Colocado de modo "claro", tais propostas parecem lógicas tendo em vista o apelo midiático e grupo gerador/mantenedor dessa ordem. Ao retiramos pessoas trans da escola, através da exclusão institucional, estaríamos preservando "nossas crianças" de possíveis abusadores e desajustes no campo educacional. Sabemos que extirpar grupos sociais, não resguarda ou beneficia qualquer instituição social, entretanto corrobora com a manutenção de poder e institucionalização (autorizada) de estratégias de controle sobre corpos outros. A estratégia se faz do uso do controle de grupos dominantes sobre grupos oprimidos, então o pânico moral é uma estratégia de controle. Por assumir meu lugar de fala (Ribeiro, 2018) busco pensar o pânico moral que foi institucionalizado e mantenedor de corpos travestis fora dos grupos merecedores de processos maiores de inclusão e cidadanização. Por mais que seja atroz, perceber que seu grupo na totalidade passa por alguma forma de inferioridade e depreciação, me faz pensar sobre os agenciamentos culturais que

\footnotetext{
${ }^{65} \mathrm{O}$ movimento Escola sem Partido surgiu com o intuito de acabar com a doutrinação política ideológica que "supostamente" ocorre constantemente nas escolas pelo Brasil. A, suposta, doutrinação política e ideológica em sala de aula ofenderia a liberdade de consciência do estudante; afrontaria o princípio da neutralidade política e ideológica do Estado; e ameaçaria o próprio regime democrático, na medida em que instrumentalizaria o sistema de ensino com o objetivo de desequilibrar o jogo político em favor de um dos "competidores".
} 
fazem com que todo um sistema estrutural social, siga pistas nos processos de exclusão trans. Escrever é uma tentativa de conversa sobre o modo histórico sobre como corpos não autorizados, resistem, nas esferas educacionais, apesar do pânico moral, da "ideologia de gênero" e sua ciclicidade.

Apesar de notório, o modo como ocorrem os agenciamentos por parte de alguns cristãos dentro desta estrutura patriarcal e cristã, nos faz perceber que grupos considerados "menores" não teriam direito a uma réplica, como no caso apresentado. Como as normas hegemônicas estão bastante arraigadas e enraizadas nas pessoas e grupos sociais, é compreensível que vejamos mulheres machistas, pessoas LGBT LGBTfóbicas, negros racistas. Existe uma estrutura que faz com que estejamos mais atentos àquilo que foge à norma, de tal maneira que nossos sentimentos são mais pungentes sobre aquilo ou aqueles que a isso escapam como escreve Bertold Bretch, "a cadela do fascismo está sempre no cio".

É quase "natural" que assim se portem, afinal, as estruturas estigmatizantes são, por todos nós, em maior ou menor grau, mantidas e repassadas. Os excluídos tentam operar os sistemas de opressão, mantendo-os ou reagindo a eles. Os corpos transgêneros em salas de aulas são o reforço da resistência, mas também o alto preço dos riscos em querer desafiar o que impõe este sistema. A internet reforçou o que supúnhamos morto, e assim também as nossas salas de aula se fizeram outras.

\section{Referências Bibliográficas}

ALTMANN, Helena. A sexualidade adolescente como foco de investimento políticosocial. Educação em Revista. Belo Horizonte. № 46, dez, 2007.

ALTMANN, Helena. Adolescent sexuality as the focus of socio-political investment. Education in Journal. Belo Horizonte. No. 46, Dec, 2007.

BUTLER, Judith. "Quadros de guerra: quando a vida é passível de luto." Rio de Janeiro: Civilização Brasileira (2015).

CARDINALI, Daniel Carvalho. "Education As A Tool Of The Constitutional Duty To Tackle Homophobia: Potentialities And Struggles." Panorama Of Brazilian Law 5.7-8 (2011): 161-193.

CARRARA, Sérgio. "Moralities, rationalities and sexual politics in contemporary Brazil." Mana (2015)

CERTEAU, M. The invention of everyday life: 1 . Arts of making. 15. ed. Petrópolis: Vozes, 2008 
CIPOLLI, Stephen, et al. "Systems and methods for error resilience and random access in video communication systems." U.S. Patent No. 9,077,964. 7 Jul 2015.

DE LAURETIS, Teresa. "The essence of the triangle or, taking the risk of essentialism seriously: Feminist theory in Italy, the US, and Britain." differences 1.2 (1989): 3-37.

FASSIN, Didier. Humanitarian reason: the moral history of the present. Univ of California Press, 2011.

FRY, Peter; CARRARA, Sérgio. "Get oriented, boy!": Where are the anthropologists in relation to pastors, geneticists and so many others in the controversy over the causes of homosexuality? Journal of Anthropology, v. 59, n. 1, p. 258-280, 2016.

GARBAGNOLI, S., (2016). Against the Heresy of Immanence: Vatican's 'Gender' as a New Rhetorical Device against the Denaturalisation of the Sexual Order. Religion and Gender. 6 (2), pp. 187-204. DOI: http://doi.org/10.18352/rg.10156

GUILLAUMIN, Colette. "A Diferença cultural." Racismo e modernidade: actas do Colóquio "Três Dias sobre o Racismo (1995): 151-153.

GONÇALVES, Luiz Carlos Kutianski. "Pensando a Escola Sem Partido e seus impactos na educação." (2017).

GONÇALVES, Daniel Maffasioli, Airton Tetelbon Stein, and Flavio Kapczinski. "Avaliação de desempenho do Self-Reporting Questionnaire como instrumento de rastreamento psiquiátrico: um estudo comparativo com o Structured Clinical Interview for DSM-IV-TR." Cadernos de Saúde Pública 24 (2008): 380-390.

JOSSO, M. C. Experience of Life and Formation. São Paulo: Cortez, 2004.

The transformation of self from the narration of life stories. Porto Alegre / RS, year XXX, n. 3 (63), p. 413-438, set./dez. 2007.

JUNQUEIRA, Rogério Diniz. "Ideologia de gênero": a gênese de uma categoria política reacionária-ou: a promoção dos direitos humanos se tornou uma "ameaça à família natural"." Debates contemporâneos sobre educação para a sexualidade. Rio Grande, RS, Ed. da FURG (2017): 25-52.

LIONÇO, Tatiana; DINIZ, Débora (Orgs.). Homophobia \& Education: a challenge to silence. Brasília: Letras Frees: EdUnB, 2009b.

LOURO, Guacira Lopes. The educated body: pedagogies of sexuality. Belo Horizonte: Authentic Publisher, 2000.

Curriculum, gender and sexuality - The "normal", the "different" and the "eccentric". In: LOURO, Guacira Lopes; FELIPE, Jane; and GOELLNER, Silvana Vilodre (Orgs.). Bodies, gender and sexuality: a contemporary debate in education. Rio de Janeiro, Petrópolis: Vozes, 9th ed., 2013.

MACEDO, Roberto Sidney. Curricular acts and pedagogical autonomy. 2013

OF BRIDGES, Júlia Clara; DA SILVA, Cristiane Gonçalves. Cisnormatividade e passabilidade: displacements and differences in the narratives of trans people. Journal Review, vol. 1, n. 8, p. 396-417, 2018

OOSTERVELD, Valerie. "The definition of gender in the Rome Statute of the International Criminal Court: A step forward or back for international criminal justice." Harv. Hum Rts. J. 18 (2005): 55. 
GONÇALVES Jr, Sara Wagner Pimenta. Corpos transgressores: Politicas de resistências. Campinas-SP. Pontes. 2018.

RIBEIRO, Djamila. What is a place of speech? Letramento Editora and Livraria LTDA, 2018.

SEFFNER, Fernando. Derivas da masculinidade: representação, identidade e diferença no âmbito da masculinidade bissexual. Paco Editorial, 2016. 